\title{
Depression during Pregnancy in a Tertiary Care Center of Eastern Nepal
}

\author{
Shakya R, ${ }^{1}$ Situala $S,{ }^{2}$ Shyangwa $P M^{1}$ \\ 'Department of Psychiatry, BPKIHS, Dharan, Nepal, ${ }^{2}$ Jiri Helminth Project, Jiri-9, Dolakha, Nepal
}

\section{ABSTRACT}

This is a cross sectional study, conducted in 45 pregnant women coming for antenatal check ups in the eastern regional hospitals in Nepal. Hamilton -Depression Scale (HAM-d) was applied after initial psychiatry work up to all women who were selected for the interview.

Analysis revealed about half of the pregnant women having some form of depression. Life events (e.g. chronic illness in the family, marital disharmony, economic crisis to sustain the family) were found to be important risk factors $(\mathrm{P}<0.05)$. Antenatal depression is a more common than generally thought.

Key words: antenatal, depression, pregnancy

\section{INTRODUCTION}

Mood disorders are twice as common in women as compared with men and frequently cluster during the childbearing years. ${ }^{1}$ Although antenatal depression has not aroused the same interest as postpartum depression, many studies have found that it is no less common. Studies reveal that approximately $10 \%$ of women suffer from clinically significant depression during pregnancy (antenatal depression). For about one third of the women who became depressed during pregnancy, this represents the first episode of major depression. ${ }^{1}$ Furthermore, women with past history of major depression are at high risk for recurrent depression, some of whom recover promptly at delivery and there is an association with puerperal mania. ${ }^{2}$ Evidence suggests that postpartum depression can be part of a continuum, with onset of illness during pregnancy. ${ }^{3}$ Other risk factors for antenatal depression include marital dissatisfaction, inadequate psychological supports, recent adverse life events, poor health behavior, lower socioeconomic status and unwanted pregnancy. ${ }^{1,4}$ Furthermore, many cultural beliefs relate the type of fetal movements to the sex and personality of the baby. Such beliefs may create depression in some women when these beliefs are not in accordance with their expectations. ${ }^{5}$

\section{MATERIAL AND METHODS}

This is a cross sectional study in pregnant women coming to the antenatal clinics in eastern region (Mechi Zonal and Ilam Hospital) of Nepal during June to December 2006. All consecutive and consenting pregnant women were selected for the study. Initially they were screened clinically i.e. psychiatry work up was done and then HAM-D applied. All women were informed about the study and written consent was taken. They were permitted to give up the interview at

\author{
Correspondence: \\ Dr. Rabi Shakya \\ Department of Psychiatry \\ BPKIHS, Dharan, Nepal. \\ Phone: 025-525555 Ext. 2347 \\ Email: shakya_rabi@yahoo.com
}


Shakya et al. Depression during Pregnancy in a Tertiary care Center of Eastern Nepal

any point of time. Uncooperative and disable patients having severe physical morbidity which interfered the interview were excluded.

Total number of pregnant women included in the study was 45 , out of which, 44 were completely interviewed. Only one woman gave up the interview during the procedure.

The data analysis was performed using the Statistical Package for Social Science (SPSS version 10.0).

\section{RESULTS}

The total number of women completely interviewed was 44. The mean age of the respondents was $24.7 \pm 4.29$ years with a range of 16 to 35 years. Among the respondents, most were literate. More than half (56.8\%) of the women were multi-gravida and rest were primigravida. Almost four fifth (84\%) of the pregnancy were wanted and planned; three of the pregnancies $(6 \%)$ were due to contraception failure. Only a few (11\%) respondents were having gestation in first trimester; about half $(48 \%)$ were in third trimester.

Table 1. Socio-obstetrical characteristics of the respondents $(n=44)$

\begin{tabular}{lccc}
\hline Characteristics & Frequency & Percent & Mean (SD) \\
\hline Age in years & 4 & 9.1 & \\
$<20$ & 21 & 47.7 & 24.7(4.29) \\
$20-25$ & 17 & 38.6 & \\
$26-30$ & 2 & 4.5 & \\
$>30$ & & & \\
Education & 40 & 90.9 \\
Literate & 4 & 9.1 \\
Illiterate & & \\
Gravida & 19 & 43.2 \\
Primi & 25 & 56.8 \\
Multi & & \\
Trimester & 5 & 11.4 \\
First & 18 & 40.9 \\
Second & 21 & 47.7 \\
Third & & \\
\hline
\end{tabular}

\section{SD- Standard Deviation}

Out of 44 women in whom HAM-D questionnaire was applied, 22 had the score greater than 7 i.e. $50 \%$ of the pregnant women had some form of depression. Out of 15 women who had experienced some life events in her personal or family life (e.g. chronic illness, marital disharmony, economic crisis, social or family rejection of the marriage), 11 (73\%) had depression. In contrast, out of 29 women who didn't have any significant life events, only 11 (38\%) had depression. Similarly, out of 10 women with past obstetric complications (abortion, neonatal death, preterm delivery, hospitalization during the delivery due to difficulty in or prolonged labor), 5 (50\%) had experienced depressive symptoms. Among 17 women who got married earlier than legal age of marriage (20 years), 11 women (65\%) had depression while only $41 \%$ women had depression among the late marriages i.e. after 20 years. Regarding the number of pregnancies, $53 \%$ of the women having first pregnancy had depression while only $48 \%$ of the multi gravida women had antenatal depression.

Among the depressed pregnant, only two had past history of psychiatric disorders and one had family history of depression.

Among the pregnant women having antenatal depression, almost all had general somatic and anxiety psychic symptoms (95\% each). Most of them (86\%) had low mood experiencing hopelessness, helplessness and worthlessness. About half of them (59\%) had sleep disturbances and nearly the same (54\%) had suicidal ideation. $50 \%$ of them agreed they had some problems psychologically though they had not sought intervention.

\section{DISCUSSION}

This study showed that about half of the pregnant women have some form of depressive symptoms which is quite higher than that shown by different studies in different parts of the world in which the prevalence of antenatal depression ranges from $6 \%$ to $25 \% .3,7,8$ This high prevalence is may be due chance as this is a hospital based study and cannot be strictly extrapolated to general population.

Life events (e.g. chronic illness in the family, marital disharmony, poor economic condition to sustain the family) were found to be associated with antenatal depression which is consistent with the finding of different studies where poor health behavior (smoking, alcohol use, increased life stress), decreased social support, first pregnancy, past history of abortion, marital disharmony were found to be associated. In this study, however past obstetric complications (abortion, neonatal death, hospital delivery due to difficulty or prolonged labor), early age of marriage, status of gravida were not statistically significantly co-related compared to other studies. ${ }^{1,4,9,10}$

Lower percentage of the depressed women having past or family history of psychiatric diseases or depression may be due to low identification of the disease itself 
Shakya et al. Depression during Pregnancy in a Tertiary care Center of Eastern Nepal

Table 2. Correlation between antenatal depression and various risk factors

\begin{tabular}{|c|c|c|c|c|c|c|}
\hline Variables & $\begin{array}{l}\text { No Depression } \\
(<7)\end{array}$ & $\begin{array}{l}\text { Depression } \\
(>7)\end{array}$ & Total & $P$ value & Fisher (2-sided) & Fisher (1-sided) \\
\hline \multicolumn{7}{|l|}{ Life event } \\
\hline No & $18(62 \%)$ & $11(38 \%)$ & 29 & & & \\
\hline Yes & $4(27 \%)$ & $11(73 \%)$ & 15 & 0.026 & 0.055 & 0.027 \\
\hline \multicolumn{7}{|l|}{ Past obs complication } \\
\hline No & $8(53 \%)$ & $7(47 \%)$ & 15 & & & \\
\hline Yes & $5(50 \%)$ & $5(50 \%)$ & 10 & 0.870 & 1.00 & 0.596 \\
\hline \multicolumn{7}{|l|}{ Age at marriage } \\
\hline$<20$ & $6(35 \%)$ & $11(65 \%)$ & 17 & & & \\
\hline$>=20$ & $16(59 \%)$ & $11(41 \%)$ & 27 & 0.122 & 0.215 & 0.108 \\
\hline \multicolumn{7}{|l|}{ Literacy } \\
\hline Literate & $21(53 \%)$ & $19(47 \%)$ & 40 & & & \\
\hline Illiterate & $1(25 \%)$ & $3(75 \%)$ & 4 & 0.294 & 0.607 & 0.303 \\
\hline \multicolumn{7}{|l|}{ Gravida } \\
\hline Primi & $9(47 \%)$ & $10(53 \%)$ & 19 & & & \\
\hline Multi & $13(52 \%)$ & 12 (48\%) & 25 & 0.093 & 1.00 & 0.5000 \\
\hline \multicolumn{7}{|l|}{ Conception } \\
\hline Planned & $20(54 \%)$ & $17(46 \%)$ & 37 & & & \\
\hline Unplanned & $1(25 \%)$ & $3(75 \%)$ & 4 & & & \\
\hline Contraception failure & $1(33 \%)$ & $2(67 \%)$ & 3 & 0.455 & & \\
\hline
\end{tabular}

Table 3. Distribution of symptoms in antenatal depression $(n=22)$

\begin{tabular}{ll}
\hline Symptoms & Frequency \\
\hline General somatic symptoms & $21(95.4 \%)$ \\
Anxiety psychic symptoms & $21(95.4 \%)$ \\
Low mood (sadness, hopelessness) & $19(86.3 \%)$ \\
Retarded work/activities & $18(81.8 \%)$ \\
Anxiety somatic symptoms & $18(81.8 \%)$ \\
Insomnia & $13(59.0 \%)$ \\
Suicidal ideation & $12(54.5 \%)$ \\
Decreased appetite and Gl symptoms & $12(54.5 \%)$ \\
Agrees having depressive symptoms & $11(50.0 \%)$ \\
\hline
\end{tabular}

in the community due to less availability of psychiatric services and social stigmatization that discourage help seek tendency.

The sample represented more literate patients, planned pregnancies, and multigravida. Although these variable have no significant co-relation with the occurrence of ante-partal depression, it may be assumed that these groups are more aware for need of regular check up and have less stigma to psychiatric help.

The clinical symptoms of depression represented more somatic symptoms, which was keeping up with studies on depression in this part of world, the reason again being acceptability of somatic problem and stigma of psychiatric problem. ${ }^{11}$

The limitation of this study is it is a cross sectional study done hospital based population. So the results of this study may not be generalized to the general population. Because of constraint of time and resources, relevant investigations to rule out organic cause for depressive symptoms were not considered.

\section{CONCLUSION}

Although the study was in a small scale and crosssectional, it can be concluded that antenatal depression is a more common than generally thought. So antenatal clinics should have facilities for early recognition of depressive symptoms because depression can adversely 
affect birth outcomes and neonatal health and, if left untreated, can persist after the birth. Differential effects of proposed factors in the development of antenatal depression are to be studied in future research, particularly in conjunction with investigation of neurohormonal variables.

\section{REFERENCES}

1. Nonacs R, Cohen LS. Assessment and treatment of depression during pregnancy: An Update. Psychiar Clin N Am 2003;26:547-62

2. Gelder MG, Lopez JJ, Andreasen NC. New Oxford Textbook of Psychiatry. 1st ed. Oxford University Press; 2003. p. 1198.

3. Ryan D, Milis L, Misri N. Depression during pregnancy. Can Fam Physician 2005;51(8): p.1087-93.

4. Zuckerman B, Amaro H, Bauchner H, Cabral H. Depressive symptoms during pregnancy due to poor health behaviours. Am J Obstet Gynecol 1989;160:1107-11.

5. Sadock BJ, Sadock VA. Kaplan and Sadock's synopsis of psychiatry: Mood disorder. 9th ed Philadelphia: Lippincott Williams and Wilkins; 2003. P. 868.

6. Hamilton M. A Rating Scale for Depression. Journal of Neurosurgery and Psychiatry 1960;23:56-62.
7. Lee DT, Chan SS, Sahota DS, Yip AS, Tsui M, Chung TK. A prevalence study of antenatal depression among Chinese women. J Affect Disord 2004;82(1):93-9.

8. Joseffson A, Garan B, Conoy N, Sydrjo G. Prevalence of depressive symptoms in late pregnancy. Acta Obstetrica et Gynecologica Scandinavica 2001;80(3):251-55.

9. Kitamura T, Shima S, Sugawara M, Toda MA. Clinical and Psychological correlates of antenatal depression: a review. Psychother Psychosom 1996;65(3):117-23.

10. Johanson R, Chapman G, Murray D, Johnson I, Cox J. The North Staffordshire Maternity Hospital prospective study of pregnancy associated depression. J Psychosom Obstet Gynecol 2000;21(2):93-7

11. Kulhara P. Phenomenology of Depression: Somatic Symptoms of Depression in India. Indian Psychiatry Society 1987. 